\title{
Earlobe pulsation: a sign of tricuspid regurgitation
}

\author{
Kiyoshi Shikino, Masatomi Ikusaka
}

General Medicine, Chiba University Hospital, Chiba, Japan

Correspondence to Dr Kiyoshi Shikino, kshikino@gmail.com

Accepted 22 November 2018

\section{DESCRIPTION}

A 72-year-old woman had been experiencing shortness of breath for 2 weeks. Her jugular venous pressure was elevated, with prominent systolic pulsations and waggling earlobes (figure 1 and video 1). The prominent pulsations were eliminated with gentle pressure at the base of the neck. Auscultation revealed a loud pulmonary component of the second heart sound and a holosystolic murmur at the left lower sternal border that increased with inspiration. Transthoracic echocardiography confirmed severe tricuspid regurgitation and a dilated inferior vena cava without respiratory fluctuation. The estimated pulmonary artery systolic pressure was $>50 \mathrm{~mm} \mathrm{Hg}$. Rightsided congestive heart failure was diagnosed and treated with oral diuretics. Within 1 week, the symptoms improved (figure 2 and video 2 ).

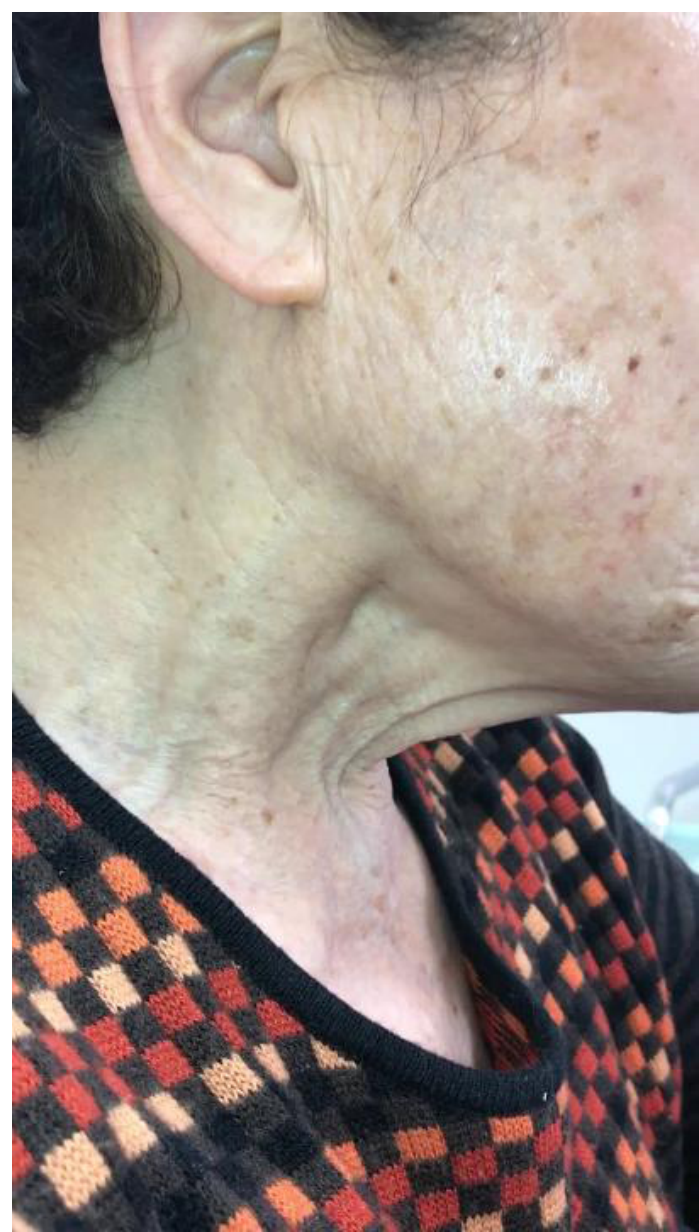

Video 1 Elevated jugular venous pressur with earlobe pulsation.

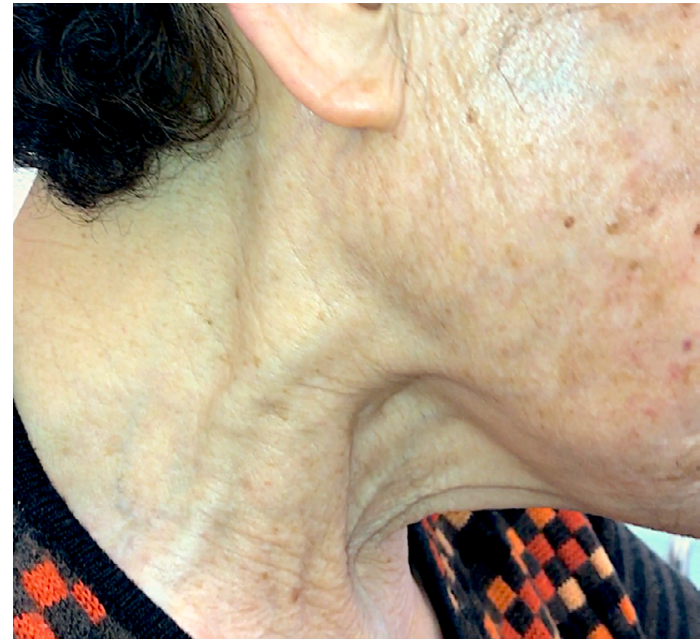

Figure 1 Elevated jugular venous pressure with earlobe pulsation.

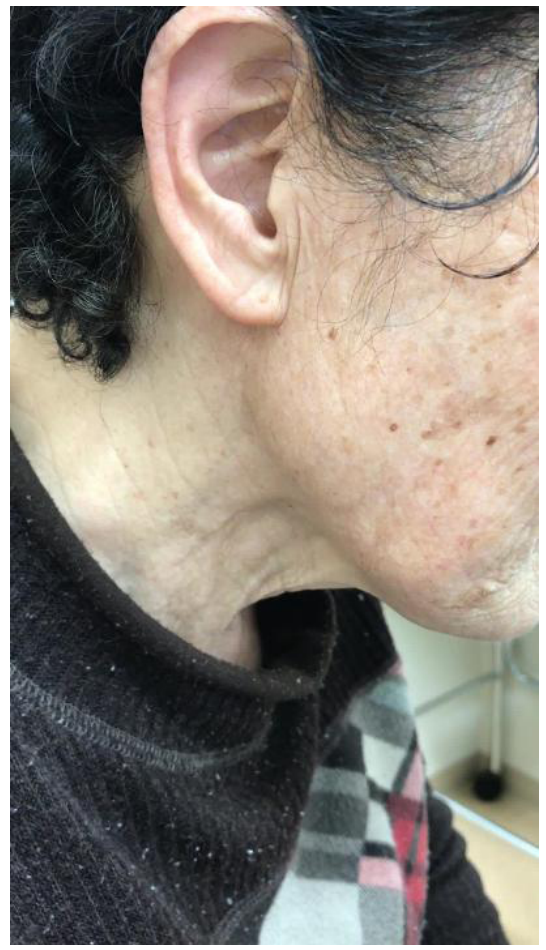

Video 2 Earlobe pulsation disappeared after treatment.

Jugular venous pulsations ascend with congestive heart failure and may reach the earlobes, causing them to pulsate. ${ }^{1}$ In severe tricuspid regurgitation, one may see movements of the earlobes coincident with systole, as the C-V wave causes them to 'waggle' with each pulsation. ${ }^{1}$ This $\mathrm{C}-\mathrm{V}$ wave of severe tricuspid regurgitation resembles the large 


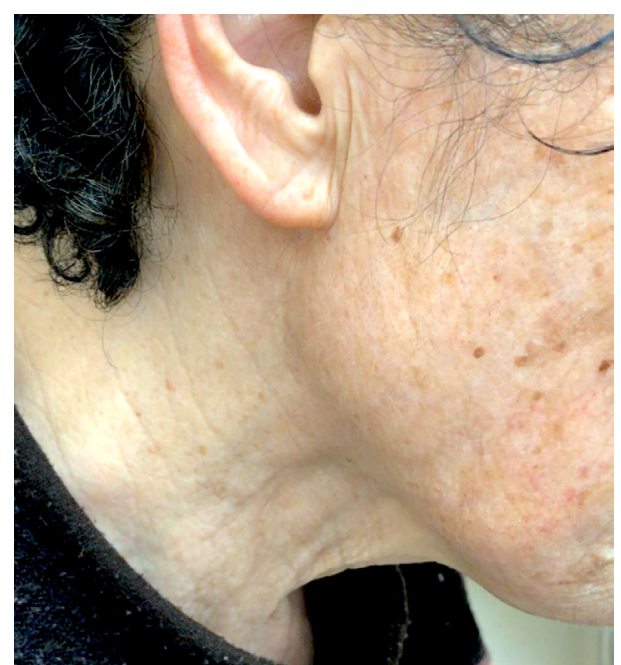

Figure 2 Earlobe pulsation disappeared after treatment.

carotid-pulse wave of severe aortic regurgitation and is often confused with it. ${ }^{2}$

\section{Learning points}

- Earlobe pulsation is indicative severe tricuspid regurgitation.

- The C-V wave of severe tricuspid regurgitation resembles the large carotid-pulse wave of severe aortic regurgitation.

Contributors KS managed patient. KS wrote the draft. MI revised this article.

Funding The authors have not declared a specific grant for this research from any funding agency in the public, commercial or not-for-profit sectors.

Competing interests None declared.

Patient consent for publication Obtained.

Provenance and peer review Not commissioned; externally peer reviewed.

\section{REFERENCES}

1 Chizner MA. The diagnosis of heart disease by clinical assessment alone. Dis Mon 2002;48:7-98.

2 Byrd MD. Lateral systolic pulsation of the earlobe: a sign of tricuspid regurgitation. Am J Cardiol 1984;54:244.

Copyright 2018 BMJ Publishing Group. All rights reserved. For permission to reuse any of this content visit https://www.bmj.com/company/products-services/rights-and-licensing/permissions/

BMJ Case Report Fellows may re-use this article for personal use and teaching without any further permission.

Become a Fellow of BMJ Case Reports today and you can:

- Submit as many cases as you like

- Enjoy fast sympathetic peer review and rapid publication of accepted articles

- Access all the published articles

Re-use any of the published material for personal use and teaching without further permission

For information on Institutional Fellowships contact consortiasales@bmjgroup.com

Visit casereports.bmj.com for more articles like this and to become a Fellow 